\title{
Saneamento básico: Concepções e percepções de estudantes do Ensino Fundamental de uma escola da Região Metropolitana de Porto Alegre
}

\author{
Basic sanitation: Conceptions and perceptions of Middle School students in Porto Alegre
} Metropolitan Area

Saneamiento básico: Concepciones y percepciones de Estudiantes de Primaria en el Área Metropolitana de Porto Alegre

\section{Resumo}

O saneamento básico é um componente essencial da vida urbana contemporânea. Desse modo, a escola necessita inserir em suas práticas educativas atividades a respeito dessa temática. Diante de tais premissas, o objetivo do presente artigo consiste em analisar o olhar de estudantes dos anos finais do Ensino Fundamental sobre saneamento básico visando obter subsídios para a construção de práticas educativas adequadas. As atividades realizadas envolveram a aplicação de questionários com perguntas abertas e fechadas e processos de exposição dialogada. As informações de âmbito qualitativo foram examinadas com a Análise de Conteúdo e as quantitativas com o Teste de Kruskal-Wallis. Os resultados indicaram a necessidade de problematizar o assunto em diferentes disciplinas, incluindo atividades que apontem as inter-relações entre os quatro âmbitos do saneamento básico visando capacitar os estudantes para os debates públicos a respeito dessa temática.

Palavras-chave: Saneamento básico; Ensino fundamental; Educação.

\begin{abstract}
Basic sanitation is an essential component of contemporary urban life. Thus, the school needs to include activities on this topic in its educational practices. Given these premises, the objective of this article is to analyze the view of students from Middle School about basic sanitation aiming to obtain subsidies for the construction of appropriate educational practices. The activities carried out involved the application of questionnaires with open and closed questions and dialogical presentations. The qualitative information was examined with Content Analysis and the quantitative information with the Kruskal-Wallis Test. The results indicated the need to problematize the subject in different disciplines, including activities that point to the interrelationships between the four areas of basic sanitation aiming to enable students for public debates on this theme.
\end{abstract}

Keywords: Basic sanitation; Middle school; Education.

\section{Resumen}

El saneamiento básico es un componente esencial de la vida urbana contemporánea. Por ello, la escuela debe incluir actividades sobre este tema en sus prácticas educativas. Dadas estas premisas, el objetivo de este artículo es analizar la visión de los alumnos de los últimos años de la Escuela Primaria sobre el saneamiento básico con el fin de obtener subsidios para la construcción de prácticas educativas adecuadas. Las actividades consistieron en la aplicación de cuestionarios con preguntas abiertas y cerradas y procesos de exposición dialogada. La información cualitativa se examinó con el Análisis de Contenido y la cuantitativa con la prueba de Kruskal-Wallis. Los resultados indicaron la necesidad de problematizar el tema en diferentes disciplinas, incluyendo actividades que señalen las interrelaciones entre las cuatro esferas del saneamiento básico con el fin de capacitar a los estudiantes para los debates públicos sobre este tema.

Palabras clave: Saneamiento; Escuela primaria; Educación. 


\section{Introdução}

A aglomeração populacional urbana faz com que surjam novas necessidades em relação à circulação, à moradia, ao abastecimento de água, entre outras necessidades básicas do ser humano. Nessa perspectiva é importante compreender que, em situações nas quais não há saneamento básico, há um pronunciado aumento na proliferação de doenças em decorrência de problemas de esgotamento sanitário, resíduos sólidos e abastecimento de água (Fantin \& Oliveira, 2014; Aguiar \& Dal-Farra, 2019).

Antigamente, o ambiente natural era considerado como fonte inesgotável de recursos a serem explorados. Atualmente há um conjunto expressivo de evidências apontando a presença de uma exploração indiscriminada e predatória da natureza em função do efeito antrópico, conduzindo à escassez dos recursos naturais, especialmente considerando que as relações entre os seres vivos e os elementos abióticos são calcadas em um processo contínuo de transformações no qual os seres vivos retiram e devolvem substâncias ao seu entorno. As formas pelas quais os seres humanos lançam os seus produtos no ambiente têm gerado inúmeros prejuízos aos seres vivos que habitam o planeta, já que os resíduos e o dejetos são lançados sem o tratamento adequado nos mananciais hídricos e no solo. A escassez de práticas adequadas de saneamento básico tem como consequência, ainda, a redução na qualidade de vida da população. Nessa perspectiva, os serviços que o compõem precisam estar adequados, reduzindo os fatores de riscos à saúde e contribuindo para a preservação ambiental (Brasil, 2001; Soares et al., 2004; Valduga \& Dal-Farra, 2015; Aguiar \& Dal-Farra, 2019).

A Lei no 9.795 (1999) relacionada à Educação Ambiental, no Artigo 2, preconiza que a sociedade mantenha a “. . . atenção permanente à formação de valores, atitudes e habilidades que propiciem a atuação individual e coletiva voltada para a prevenção, a identificação e a solução de problemas ambientais”. Considerando que o ambiente escolar se constitui em espaço propício para multiplicar conhecimentos nas comunidades, é importante construir práticas educativas para tornar o aluno capaz de refletir e agir de forma abalizada, tanto no ambiente escolar quanto na convivência em sociedade. Com base em tais premissas, o objetivo do presente artigo consiste em analisar as percepções e concepções a respeito do saneamento básico de alunos pertencentes aos anos finais do Ensino Fundamental de uma escola estadual da Região Metropolitana de Porto Alegre visando obter subsídios para a construção de ações em relação à essa temática no referido nível de ensino.

\subsection{Saneamento Básico e a Educação}

No período colonial brasileiro, nas cidades que iniciavam sua urbanização, tais como Salvador, Rio de Janeiro e Recife, havia a preocupação com o povoamento e a distribuição da água dos rios para as comunidades mais distantes, gerando o sistema de calhas de distribuição de água para a população, assim como a criação de chafarizes, fontes e bicas nos centros urbanos para que as pessoas de baixa renda conseguissem ter acesso à água de forma gratuita. Já na questão do esgoto, muitos escravos eram encarregados de fazer o transporte dos resíduos das residências até valas que desembocavam no mar. No entanto, a preocupação com o saneamento era escassa (Murtha et al., 2015).

Por definição, saneamento ambiental consiste no:

. . . conjunto de ações socioeconômicas que têm por objetivo alcançar níveis de Salubridade Ambiental, por meio de abastecimento de água potável, coleta e disposição sanitária de resíduos sólidos, líquidos e gasosos, promoção da disciplina sanitária de uso do solo, drenagem urbana, controle de doenças transmissíveis e demais serviços e obras especializadas, com a finalidade de proteger e melhorar as condições de vida urbana e rural (Brasil, 2018b, p. 21).

A Lei $n^{\circ} 11.445$ (Brasil, 2007) trouxe as diretrizes do saneamento básico, demonstrando que toda a população tem o direito de ter água tratada, manejo correto de resíduos sólidos e esgotamento sanitário. Esse dispositivo legal se constituiu em ponto de partida para que os municípios brasileiros tomassem medidas mais efetivas visando ao acesso da população a esse 
serviço essencial no desenvolvimento de um país. Os serviços de água tratada, coleta e tratamento dos esgotos contribuem decisivamente para a qualidade de vidas das pessoas, sobretudo no que tange à saúde infantil pela redução da mortalidade, além de gerar melhorias na educação, na expansão do turismo, na valorização dos imóveis, na renda do trabalhador, na despoluição dos rios e na preservação dos recursos hídricos em geral (Instituto Trata Brasil, 2012).

O município no qual está localizada a escola pertence à Região Metropolitana de Porto Alegre, possuindo um Índice de Desenvolvimento da Educação Básica de 4,9 nos anos iniciais do Ensino Fundamental e de 3,6 nos anos finais (Brasil, 2021a) e necessitando, tal como a grande maioria de cidades brasileiras, de melhorias nas condições de saneamento básico. No entanto, junto às medidas estruturais de implantação e manutenção dos serviços de saneamento são necessárias ações educacionais que possam contribuir para que a população conheça essa temática, aprimorando as suas concepções e percepções a respeito da sua importância para que participem do debate público de forma abalizada.

De acordo com a Base Nacional Comum Curricular (BNCC) (Brasil, 2018a) a escola contribui para o delineamento do projeto de vida dos estudantes nos anos finais do Ensino Fundamental ao estabelecer uma articulação, não somente com os anseios dos jovens em relação ao seu futuro, como também com a continuidade dos estudos no Ensino Médio. Esse processo de reflexão sobre o que cada estudante almeja para o futuro conduz para o desenvolvimento pessoal e social de cada um.

Sendo o ambiente escolar um espaço social formado por complexas redes de interações, apresentando multiplicidades de significados, as dimensões institucional e pedagógica estão entremeadas com a dimensão cultural (Kutter, 2010). Desse modo, a escola possui um papel fundamental na viabilização de condições propícias para o aprendizado do aluno, fornecendo incentivo para a atuação dos professores e alunos. No olhar de Pereira (2015), a escola é uma instituição dinâmica que precisa estar sintonizada com a vida contemporânea, proporcionando experiências cognitivas, socioculturais e afetivas voltadas para a formação global do aluno. Para essa finalidade torna-se necessário ocorrer mudanças nos processos de ensino e aprendizagem para que os estudantes tenham a oportunidade de desenvolver suas habilidades no sentido de contribuir para a compreensão e solução dos problemas de sua comunidade (Valduga \& Dal-Farra, 2015).

A presente pesquisa se ancora nas habilidades presentes na BNCC quando preconizam a interpretação das condições de saúde da comunidade, cidade ou estado, com base na análise e comparação de indicadores de saúde, tais como, taxa de mortalidade infantil, cobertura de saneamento básico e incidência de doenças de veiculação hídrica, atmosférica entre outras patologias, considerando a educação como processo de formação de estudantes que atuam como multiplicadores de conhecimentos na comunidade em que habitam (Brasil, 2018a).

\section{Metodologia}

As coletas de dados foram realizadas no segundo semestre de 2020 com estudantes de uma escola estadual localizada na Região Metropolitana de Porto Alegre. O Projeto da presente investigação foi aprovado pelo Comitê de Ética em Pesquisa em Seres Humanos da Universidade Luterana do Brasil - CAAE 34352920.0.0000.5349.

Inicialmente foi realizada a aplicação de um questionário com perguntas abertas e fechadas respondido pelos estudantes do $6^{\circ}$ ao $9^{\circ}$ ano que eles poderiam responder com a consulta à referências na internet sobre saneamento básico. Em um segundo momento foram aplicadas práticas educativas referentes à temática, contextualizando o assunto no âmbito da cidade na qual a escola está localizada e versando especificamente sobre os quatro âmbitos do saneamento básico. As atividades envolveram a exposição dialogada e a leitura pelos estudantes de um e-book construído especialmente para o desenvolvimento da pesquisa contendo informações dos serviços no município e sugestão de práticas de conscientização e de possíveis experiências no âmbito das Ciências da Natureza. No terceiro momento da pesquisa foi aplicado um questionário após a atividade sobre os serviços do saneamento básico do município visando a compreensão dos processos de aprendizagem 
realizados pelos estudantes.

O conjunto de informações produzido foi examinado, no caso das questões abertas, com a Análise de Conteúdo (Bardin, 2011) com a construção das categorias definidas a priori segundo os quatro âmbitos do saneamento básico estatuídos pela Lei $\mathrm{n}^{\circ} 11.445$ (Brasil, 2007), que estabelece as Diretrizes Nacionais para o Saneamento Básico e, em seu artigo $3^{\circ}$, considera:

I - Saneamento básico: conjunto de serviços, infraestruturas e instalações operacionais de:

a) abastecimento de água potável: constituído pelas atividades, infraestruturas e instalações necessárias ao abastecimento público de água potável, desde a captação até as ligações prediais e respectivos instrumentos de medição;

b) esgotamento sanitário: constituído pelas atividades, infraestruturas e instalações operacionais de coleta, transporte, tratamento e disposição final adequados dos esgotos sanitários, desde as ligações prediais até o seu lançamento final no meio ambiente;

c) limpeza urbana e manejo de resíduos sólidos: conjunto de atividades, infraestruturas e instalações operacionais de coleta, transporte, transbordo, tratamento e destino final do lixo doméstico e do lixo originário da varrição e limpeza de logradouros e vias públicas;

d) drenagem e manejo das águas pluviais urbanas: conjunto de atividades, infraestruturas e instalações operacionais de drenagem urbana de águas pluviais, de transporte, detenção ou retenção para o amortecimento de vazões de cheias, tratamento e disposição final das águas pluviais drenadas nas áreas urbanas.

As questões de âmbito quantitativo foram respondidas com escores de 1 a 5, sendo aplicado o teste não-paramétrico de Kruskal-Wallis para verificar a significância estatística das médias obtidas para cada variável. A integração entre os componentes qualitativos e quantitativos configura o presente estudo como Pesquisa com Métodos Mistos realizado com um Design Convergente e a junção ("merge") dos resultados obtidos com as questões abertas e as questões fechadas (Dal-Farra \& Fetters, 2017).

\section{Resultados e Discussão}

O grupo que participou das atividades da pesquisa, apresentava, predominantemente, idades entre 11 e 17 anos, com média de 15 anos, sendo $51 \%$ do sexo feminino e $49 \%$ do sexo masculino. Do total de alunos, $19 \%$ eram do $6^{\circ}$ ano, $16 \%$ do $7^{\circ}$ anos, $36,5 \%$ do $8^{\circ}$ ano e $28,5 \%$ do $9^{\circ}$ ano, totalizando 82 alunos na pré-atividade e 45 na pós-atividade. Os estudantes em questão habitavam residências com, em média, quatro moradores, sendo oito deles coabitando com mais cinco pessoas. Do total, $79,3 \%$ informaram que em suas casas havia apenas um banheiro. Ao serem questionados (pré-atividade) se sabiam o significado de saneamento básico, $62 \%$ dos estudantes responderam afirmativamente, embora, em outra questão, apenas 15,9\% tenham assinalado corretamente os quatro âmbitos do saneamento básico, tal como apresentado na Tabela 1. Ressalta-se que foi permitido, caso os estudantes considerassem necessário, a consulta na internet para responder as questões. 
Tabela 1 - Âmbitos do saneamento básico segundo os estudantes.

\begin{tabular}{|c|c|c|}
\hline & PRÉ-ATIVIDADE & PÓS-ATIVIDADE \\
\hline Água, esgoto, resíduos sólidos, drenagem urbana & $13(15,9 \%)$ & $36(80,0 \%)$ \\
\hline Água, esgoto, resíduos sólidos & $9(11,0 \%)$ & $3(6,7 \%)$ \\
\hline Água, esgoto, drenagem urbana & $1(1,2 \%)$ & - \\
\hline Água, drenagem urbana e resíduos sólidos & $1(1,2 \%)$ & $1(2,2 \%)$ \\
\hline Água, esgoto & $9(11,0 \%)$ & - \\
\hline Água, resíduos sólidos & $3(3,7 \%)$ & \\
\hline Resíduos sólidos, drenagem urbana & - & $1(2,2 \%)$ \\
\hline Esgoto, resíduos sólidos & $3(3,7 \%)$ & $1(2,2 \%)$ \\
\hline Água & $2(2,4 \%)$ & $2(4,5 \%)$ \\
\hline Esgoto & $4(4,9 \%)$ & - \\
\hline Resíduos sólidos & $4(4,9 \%)$ & - \\
\hline Não souberam/Respostas inespecíficas & $33(37,8 \%)$ & $1(2,2 \%)$ \\
\hline Total de estudantes & 82 & 45 \\
\hline
\end{tabular}

Fonte: Autores (2021).

Vale ressaltar, também, que a localidade na qual os estudantes habitam apresenta problemas de abastecimento de água e, em alguns casos, esgoto à céu aberto, sendo possível observar durante as atividades o interesse por parte dos estudantes a respeito da temática, o que proporcionou um aumento pronunciado de respostas corretas na pós-atividade (82\%) e uma redução drástica de respostas em branco ou respostas inespecíficas de 37,8\% (pré-atividade) para 2,2\% (pós-atividade). Antes da pesquisa poucos alunos conseguiram relacionar que a drenagem urbana fazia parte dos serviços do saneamento básico corroborando os resultados de Valduga e Dal-Farra (2015).

Quando perguntados se havia "rede de drenagem composta de bocas de lobo ("bueiros") e galerias de águas pluviais na rua onde reside?" um total de 15,8\% respondeu que não, 26,8\% deles afirmou não saber, e 57,4\% responderam afirmativamente. Por outro lado, 59,8\% dos estudantes haviam informado que as ruas próximas à sua casa ficavam alagadas em dias chuvosos, ou seja, embora reconheçam no cotidiano a relevância da drenagem urbana, os estudantes não a relacionam diretamente como sendo um âmbito do saneamento básico.

Dutra e Vieira (2020) enfatizam a relevância da percepção do alagamento por parte da população como medida voltada para a coletividade, e não apenas quando acontece na região delimitada pelo lote ou moradia. Afastar a água superficial o mais rápido possível do meio é transferir o problema para a jusante da bacia. Nessa perspectiva, segundo as autoras, a falta de compreensão da população sobre o sistema de drenagem da região sinaliza o olhar que negligencia a participação ativa na gestão da cidade. Assinalam, ainda, Dutra e Vieira (2020) que quando o residente não identifica os danos causados pelas inundações, transparece a falta de conhecimento sobre o assunto e a desatenção com o meio urbano em que convive.

Transformando os dados em uma análise separada para cada componente do saneamento básico, foi possível observar que o esgotamento sanitário foi mencionado por 39 estudantes, correspondendo a 47,6\% do total na pré-atividade, número semelhante ao abastecimento de água, mencionado por 38 participantes (46,3\%), seguido pelos resíduos sólidos, com 33 estudantes $(40,2 \%)$ e pela drenagem urbana, citada por 15 respondentes $(18,3 \%)$.

Tais resultados demonstram a necessidade de construção de um processo educacional que aborde esses aspectos no âmbito sistêmico, envolvendo as inter-relações entre os quatro componentes desse crucial aspecto da vida contemporânea, tal como assinalam Aguiar e Dal-Farra (2019) ao abordar os quatro âmbitos com estudantes do ensino fundamental contextualizando com os componentes curriculares de cada ano.

Conforme Mora e Poletto (2013) é importante que as intervenções pedagógicas produzam melhorias conceituais e atitudinais, contribuindo para a construção de novos conhecimentos e, dessa maneira, gerando mudanças comportamentais mediante a sensibilização dos alunos no decorrer do processo de ensino e aprendizagem, já que as escolas, segundo Pelenda e 
Berté (2021) são essenciais na disseminação de conceitos ambientais, contribuindo para a formação de cidadãos críticos a respeito do entorno em que vivem (Jeovanio-Silva et al., 2018).

Na pré-atividade, os estudantes responderam ainda uma questão a respeito da avaliação que tinham do bairro em que habitavam, com escores de 1 (péssimo) a 5 (ótimo). Os resultados estão na Tabela 2.

Tabela 2 - Situação do bairro segundo a percepção dos estudantes.

\begin{tabular}{lcc}
\hline \multicolumn{1}{c}{ Questão } & Média & Desvio Padrão \\
\hline Como você avalia a situação de seu bairro quanto ao abastecimento de água & $3,76 \mathrm{a}$ & 0,91 \\
Como você avalia a situação de seu bairro quanto à natureza & $3,38 \mathrm{ab}$ & 1,22 \\
Como você avalia a situação de seu bairro quanto à saúde & $3,35 \mathrm{ab}$ & 1,32 \\
Como você avalia a situação de seu bairro quanto ao lixo & $3,15 \mathrm{~b}$ & 1,20 \\
Como você avalia a situação de seu bairro quanto ao esgoto & $2,89 \mathrm{~b}$ & 1,19 \\
Como você avalia a situação de seu bairro quanto à drenagem urbana & $2,89 \mathrm{~b}$ & 1,14 \\
\hline
\end{tabular}

Fonte: Autores (2021).

Verifica-se, analisando as médias dos escores atribuídos pelos estudantes que, em geral, a avaliação das condições em que moram é negativa, à exceção do abastecimento de água (3,76), embora esse valor não tenha sido estatisticamente diferente das questões "natureza" e "saúde". Os demais apresentaram médias próximas ao valor intermediário para os resíduos sólidos, ou, abaixo dele, no caso de esgoto e drenagem urbana. Provavelmente, se houvessem respondido à questão após as atividades, conhecendo melhor a temática, os valores fossem ainda menores. Segundo dados do Sistema Nacional de Informações sobre Saneamento, o índice de esgoto tratado no Brasil é 49,1\% (Brasil, 2021b), demonstrando que o olhar dos participantes possui semelhança com a realidade do país.

Diante da relevância de abordagens a respeito do saneamento básico no Ensino Fundamental, os estudantes foram questionados a respeito da relevância de cada componente curricular abordar a temática em suas atividades. Os resultados estão na Tabela 3.

Tabela 3- Relevância de cada componente curricular segundo a percepção dos estudantes.

\begin{tabular}{lll}
\hline Componente curricular & Média & Desvio-padrão \\
\hline Ciências & $4,32 \mathrm{a}$ & 0,98 \\
Geografia & $3,62 \mathrm{~b}$ & 1,32 \\
História & $2,96 \mathrm{c}$ & 1,44 \\
Português & $2,89 \mathrm{c}$ & 1,31 \\
Matemática & $2,45 \mathrm{c}$ & 1,30 \\
\hline
\end{tabular}

Fonte: Autores (2021).

Verifica-se que os estudantes consideraram relevante as disciplinas de Ciências e, em menor grau, Geografia para abordar a temática saneamento básico. Esse olhar precisa ser problematizado com os estudantes em virtude das amplas possibilidades de trabalhar o assunto por meio das Ciências Humanas e da Matemática. Em que pese, portanto, a participação da temática saneamento básico em nosso cotidiano e a pluralidade de questões a serem incluídas em processos educacionais relevantes a esse respeito, os valores de concordância foram acima do escore intermediário apenas para Ciências e Geografia, embora a História possa contribuir decisivamente para a compreensão de tais processos na atualidade, assim como esse pode ser um excelente tema para a realização de produções textuais pelos estudantes.

Criar condições para haver uma participação mais ativa dos alunos implica na mudança da prática discente e no desenvolvimento de estratégias que garantam a organização de um aprendizado mais interativo e intimamente ligado com as situações cotidianas, demandando processos inovadores de aprendizagem (Camargo \& Daros, 2018). Conforme o Referencial 
Curricular Gaúcho, as temáticas contemporâneas precisam ser incorporadas nas áreas já existentes e no trabalho educativo da escola, garantindo a transversalidade, com foco nas problemáticas sociais que o contexto apresenta (Rio Grande do Sul, 2018).

Por tais razões, a abordagem dos grandes temas contemporâneos e a sua aplicação no cotidiano de cada bairro ou comunidade produzem relevantes conhecimentos da localidade onde o sujeito se encontra, indicando as possibilidades de mudança da realidade com ações mais efetivas, tanto por parte do cidadão, como do poder público. A referida mudança ocorre a partir do reconhecimento do ambiente vivenciado através de um despertar e de uma intervenção efetiva por meio da educação que pode ser tanto formal quanto informal.

\section{Considerações Finais}

Os processos de ensino e aprendizagem se tornam mais efetivos quando os estudantes participam ativamente das ações, o que demanda compreender as percepções e concepções deles a respeito das temáticas trabalhadas, especialmente no que se refere ao ambiente natural. Desse modo, as práticas educativas precisam sensibilizar os estudantes a respeito de temas cruciais como o saneamento básico, buscando construir uma aprendizagem significativa em relação aos serviços que estão sendo prestados em sua comunidade. É perceptível que a educação contribui na formação do cidadão, assim como a convivência em sociedade requer a cooperação de cada um para obter melhorias no espaço em que vivemos. No entanto, para isso ocorrer, é necessário conhecer os serviços essenciais e as formas de reivindicação em questões cruciais como o saneamento básico. Agindo em conjunto, a população conquista a melhoria das condições ambientais em decorrência do tratamento adequado dos dejetos e do cuidado com os mananciais hídricos.

Diante da relevância de abordar as questões do saneamento básico no Ensino Fundamental, o presente estudo, destinado à obtenção de subsídios para a construção de práticas educativas com essa temática, identificou a relevância de problematizar a questão em diferentes componentes curriculares, além de evidenciar a necessidade de uma abordagem de caráter sistêmico envolvendo os quatro âmbitos desse crucial componente da vida urbana incluindo, o abastecimento de água, o esgotamento sanitário, a drenagem urbana e os resíduos sólidos/limpeza urbana. Com essa perspectiva, torna-se possível sensibilizar os estudantes para que contribuam nos debates a respeito do assunto, se constituindo em multiplicadores desses conhecimentos na comunidade em que habitam, contribuindo para a qualidade de vida da população, para a preservação dos componentes abióticos e para a sobrevivência das espécies que coabitam o planeta conosco.

Com base em tais premissas, a realização de estudos futuros com estudantes de outras escolas permitirá compreender melhor a forma pela qual é possível incluir a temática em tela nos programas curriculares seja no Ensino Fundamental ou no Ensino Médio.

\section{Agradecimentos}

O presente trabalho foi realizado com apoio da Coordenação de Aperfeiçoamento de Pessoal de Nível Superior Brasil (CAPES) - Código de Financiamento 001.

\section{Referências}

Aguiar, M. M., \& Dal-Farra, R. A. (2019). Imagens, escores, concepções e percepções: o saneamento básico no olhar de estudantes de ensino fundamental. Acta Scientiae, 21(6), 47-65. http://www.periodicos.ulbra.br/index.php/acta/article/view/5444

Bardin, L. (2011). Análise de conteúdo. Lisboa: Edições 70.

Brasil. (2007). Lei $n^{o} 11.445$, de janeiro de 2007. Diretrizes nacionais para o saneamento básico. http://www.planalto.gov.br/ccivil_03/_ato20072010/2007/lei/L11445compilado.htm

Brasil. (1999). Lei $n^{\circ} 9.795$, de abril de 1999. http://www.planalto.gov.br/ccivil_03/leis/19795.htm 
Research, Society and Development, v. 10, n. 5, e42110514815, 2021

(CC BY 4.0) | ISSN 2525-3409 | DOI: http://dx.doi.org/10.33448/rsd-v10i5.14815

Brasil. (2001). Ministério de Educação. Educação para Jovens e Adultos Ensino Fundamental: proposta curricular. de http://www.portal.mec.gov.br/index.php.

Brasil. (2018a). Ministério de Educação. Base Nacional Comum

http://basenacionalcomum.mec.gov.br/images/BNCC_EI_EF_110518_versaofinal_site.pdf

Brasil. (2018b). Ministério da Saúde. FUNASA. Programa Sustentar: saneamento e sustentabilidade em áreas rurais. http://www.funasa.gov.br/documents/20182/21862/sustentar_publicacao/915644d2-fb28-409c-a7ca-c3cff0e59e98

Brasil. (2021a). Instituto Brasileiro de Geografia e Estatística. Alvorada. https://cidades.ibge.gov.br/brasil/rs/alvorada/panorama

Brasil. (2021b). Ministério do Desenvolvimento Regional. Sistema Nacional de Informações sobre Saneamento. http://www.snis.gov.br/painel-informacoessaneamento-brasil/web/painel-esgotamento-sanitario

Camargo. F., \& Daros. T. (Orgs.). (2018). A sala de aula inovadora: estratégias pedagógicas para fomentar o aprendizado ativo. Porto Alegre: Penso.

Dal-Farra, R. A., \& Fetters, M. D. (2017). Recentes avanços nas pesquisas com métodos mistos: aplicações nas áreas de educação e ensino. Acta Scientiae, 19(3), 466-492. http://www.periodicos.ulbra.br/index.php/acta/article/view/3116/2368

Dutra, M. C. S., \& Vieira, C. L. (2020). Percepção da comunidade quanto à necessidade de implantação de medidas de drenagem urbana com controle na fonte: um estudo de caso em uma sub-bacia de Feira de Santana-BA. Anais do $13^{\circ}$ Encontro Nacional de Águas Urbanas. de http://abrh.s3.amazonaws.com/Eventos/Trabalhos/131/XIIIENAU-IIISSRU0033-1-20201012-182249.pdf

Fantin, M. E., \& Oliveira, E. (2014) Educação Ambiental, saúde qualidade de vida. Curitiba: InterSaberes.

Instituto Trata Brasil. (2012). Atendimento de água. http://www.tratabrasil.org.br/saneamento/objetivos-do-desenvolvimento-sustentavel

Jeovanio-Silva, V. R. M., Jeovanio-Silva, A. L. J., \& Cardoso, S. P. (2018). Um olhar docente sobre as dificuldades do trabalho da educação ambiental na escola. Revista de Ensino de Ciências e Matemática, 9(5), 256-272. http://revistapos.cruzeirodosul.edu.br/index.php/rencima/article/view/1357

Kutter, A. P. Z. (2010). A Educação em Ciências Biológicas na Educação de Jovens e Adultos (EJA): uma experiência etnográfica na escola. [Dissertação de Mestrado, Universidade Federal do Rio Grande do Sul]. Recuperado em 07 março, 2021, de http://hdl.handle.net/10183/26061

Mora, S. M., \& Poletto. R. S. (2013). Metodologia de ensino no estudo sobre saneamento urbano. Os desafios da escola pública paranaense na perspectiva do professor, 1, 2-17. http://www.diaadiaeducacao.pr.gov.br/portals/cadernospde/pdebusca/producoes_pde/2013/2013_uenp_cien_artigo_sandra_maria_mora.pdf

Murtha, N. A., Castro, J. E., \& Heller, L. (2015). Uma perspectiva histórica das primeiras políticas públicas de saneamento e de recursos hídricos no brasil. Ambiente \& Sociedade, 18(3), 193-210.

Pelenda, A. M, \& Berté, R. (2021). Educação ambiental: construindo valores humanos através da educação. Curitiba: InterSaberes.

Pereira, E. G. C. (2015) Ações pedagógicas para a educação ambiental: ampliando o espaço da ação docente. [Tese de Doutorado, Instituto Osvaldo Cruz]. Recuperado em 02 de março de 2021, de https://www.arca.fiocruz.br/handle/icict/14236

Rio Grande do Sul. (2018). Referencial gaúcho: ciências da natureza. Porto Alegre: Secretaria de Estado da Educação. Recuperado em 02 de março de 2021 , de http://portal.educacao.rs.gov.br/Portals/1/Files/1530.pdf

Soares, B. E. $\quad$ C., Navarro, M. A., \& $\quad$ Ferreira, A. $\quad$ P. $\quad$ (2004). Ciências $\quad$ \& $\quad$ Cognição, 2, 42-49. http://pepsic.bvsalud.org/scielo.php?script=sci_arttext\&pid=S1806-58212004000200005\&lng=pt\&tlng=pt.

Valduga. M. \& Dal-Farra.R.A. (2015). Saneamento básico: práticas educativas no ensino fundamental. Acta Scientiae, 17(3), 766-780. http://www.periodicos.ulbra.br/index.php/acta/article/view/1537/1317 